\title{
Differential visual depth threshold of the chick'
}

\author{
RICHARD D. WALK, TONI L. FALBO AND CAROLINE \\ LEBOWITZ, PROSRAM IN COGNITIVE AND PERCEPTUAL \\ DEVELOPMENT, GEORGE WASHINGTON UNIVERSITY, \\ Washington, D. C. 20006
}

The differential visual depth threshold of the chick was tested on the visual cliff. The chicks chose the shallow side reliably when the deep side was 2 in. or more below the shallow side. At 1-3/4 in., 1-1/2 in. or 1 in. visual distance of the deep side below the glass, the shallow side was chosen at a chance level.

Chicks are known to discriminate gross visual depth more accurately than do rats. Walk \& Gibson (1961) reported about $100 \%$ choice of the shallow side of the visual cliff by day-old chicks when the deep side is $10 \mathrm{in}$. below the glass. It is unknown, however, whether the chick is also more sensitive to differential visual depth, a psychophysical method that can investigate more precisely the efficiency of motion parallax in the freely moving animal.

The differential threshold for visual depth is secured on the visual cliff by allowing the deep side to approach the shallow side. Booher \& Walk (1968) found that the approximate threshold for visual depth in the hooded rat is around 3-1/2 in.: the deep side must be at least $3-1 / 2$ in. below the shallow side before the rat chooses the shallow side about $75 \%$ of the time.

This study was performed to estimate the efficiency of visual depth perception in the chick by investigating the differential visual depth threshold.

Method

An apparatus built by Booher (1967), also described in Booher \& Walk (1968), was used. It allows the deep side to approach the shallow side while illumination is kept constant. One in. red and white checks were used on the shallow and the deep sides. All illumination came from below, through the checked patterns, and illumination was equated on the two sides (about $18 \mathrm{ft}-\mathrm{c}$ ). The chick was placed on a center board 1-1/2 in. high on top of which was an electrified grid. ${ }^{2}$ A standard laboratory shock source and a grid scrambler electrified the grid. The animal's feet were first dipped in electrode cream and the chick was then placed on the grid. If the animal did not move off of the center board in $30 \mathrm{sec}$, $40 \mathrm{~V}$ were delivered to the grid, and the shock was raised $10 \mathrm{~V}$ every $15 \mathrm{sec}$ until the animal moved off the grid. Research by Quinta (1966) and by Karmel (1966) has shown that the use of electric shock reduced response latencies, but it did not affect choice behavior on the visual cliff.

The Ss were 93 day-old chicks, 24 White Leghorns and 69 New Hampshire Reds, secured from a commercial hatchery. Three groups were used: a batch of 24 New Hampshires, a batch of 24 Leghorns and a batch of 45 New Hampshires.

The first study used visual depths on the deep side of 4 in., 2 in., 1-1/2 in. and $1 \mathrm{in}$. Animals were used several times, but an animal was never tested twice on the same visual depth. The second study used visual depths of 4 in., 2 in., 1-3/4 in. and 1-1/2 in. As in the first study, the animals were tested more than once, but they were only tested once at any one visual depth. The third study used visual depths of 2 in., 1-3/4 in., and 1-1/2 in. Each animal was tested once, 15 animals at each visual depth.

\section{Results}

The results are shown in Table 1. The first study showed good discrimination at 4 in. and 2 in. of visual depth, but no preference for the shallow side at visual depths of $1-1 / 2$ in. or 1 in. The second study showed accurate discrimination at 4 in. and 2 in., replicating the first study, but no preference for the shallow side at visual depths of $1-3 / 4$ in. or $1-1 / 2$ in. The third study used independent groups to show, again, good discrimination at a depth of 2 in., but chance choice of the shallow or the deep sides at $1-3 / 4$ in. or $1-1 / 2$ in.

Since no animal was run more than once at the same depth, the shallow-deep distribution of responses can be tested in the totals column of Table 1. The choice of the shallow over the deep side at $4 \mathrm{in}$. and at $2 \mathrm{in}$. of differential visual depth is highly significant ( $p$ $<.001$ ), but the 1-3/4 in., 1-1/2 in. and $1 \mathrm{in}$. visual depths are not significantly different from chance. Also, one can combine the independent 2 in. groups from Study I with those in Study III to yield 33 shallow and 5 deep descents, and these can be compared with the 1-3/4 in. groups from Study II and Study III where 9 shallow and 13 deep responses were secured. The difference between the two depths, only $1 / 4$ in. apart, is highly significant using chi-square $\left(x^{2}=11.90, \mathrm{p}<.001\right.$, with $\left.1 \mathrm{df}\right)$. Such a sudden jump from chance responding to virtual complete choice of the shallow side is rather suprising and should be checked using other conditions.

Discussion

The chick's threshold for differential visual depth is at around 2 in. separation of the deep and shallow sides. This is much better than the discrimination of differential visual depth in the hooded rat where about 3-1/2 in. of difference between the two sides is needed for the animal to choose the shallow side reliably (Booher \& Walk, 1968). Walk \& Bond (1968) had to use 4 in. of differential visual depth with the hooded rat to get light-reared animals to choose the shallow side reliably. They also found that the motion sensitivity of dark-reared animals was impaired since these animals chose the shallow side at $8-1 / 2$ in. or 10 in. differental visual depth, but not at the 4 in. visual depth. Unpublished research with the $3 / 4$ in. high center board on the Booher apparatus would estimate that the differential visual depth threshold of the beagle puppy and the kitten is somewhere between 3 and $4 \mathrm{in}$. of differential visual depth. On a larger model of the visual cliff human infants chose the shallow side reliably when the deep side was 5 in. below the glass, but discrimination was worse than at visual depths of 10 or more in. (Walk, 1967).

The chick, thus, is the animal most sensitive to differential visual depth of the organisms tested so far. This applies to the conditions of the present study, however, and should be checked with a wider range of conditions.

\section{REFERENCES}

BOOHER, H. R. Differentail visual depth perception threshold in the hooded rat. Unpublished M. A. thesis, George Washington Univ., 1967.

BOOHER, H. R., \& WALK, R. D. Apparatus for the differential visual depth threshold and its determination in the hooded rat. Psychon. Sci, in press. KARMEL, B. Z. The effect of complexity, amount of contour, element size, and element arrangement on visual preference and behavior in the hooded rat, domestic chick and human infant. Unpublished doctoral dissertation, George Washington Univ., 1966.

Table 1

Choices of Shallow and Deep Sides for the Three Studies with Visual Depth Varied

\begin{tabular}{|c|c|c|c|c|c|c|c|c|c|c|c|}
\hline \multirow{2}{*}{$\begin{array}{l}\text { Visual } \\
\text { Depth }\end{array}$} & \multirow[b]{2}{*}{$\mathrm{N}$} & \multicolumn{2}{|l|}{ Study I } & \multicolumn{2}{|r|}{ Study II } & \multirow[b]{2}{*}{ Deep } & \multicolumn{2}{|c|}{ Study III } & \multirow[b]{2}{*}{ Deep } & \multirow{2}{*}{$\begin{array}{l}\text { Totals } \\
\text { Shallow }\end{array}$} & \multirow[b]{2}{*}{ Deep } \\
\hline & & Shallow & Deep & $\mathrm{N}$ & Shallow & & $\mathrm{N}$ & Shallow & & & \\
\hline $4 \mathrm{in.}$ & 18 & 16 & 2 & 24 & 21 & 3 & & & & 39 & 5 \\
\hline $2 \mathrm{in.}$ & $24^{*}$ & 20 & 3 & 15 & 10 & 5 & 15 & 13 & 2 & 43 & 10 \\
\hline $1-3 / 4 \mathrm{in}$ & & & & 7 & 2 & 5 & 15 & 7 & 8 & 9 & 13 \\
\hline $1-1 / 2$ in. & 8 & 3 & 5 & 14 & 9 & 5 & 15 & 7 & 8 & 19 & 18 \\
\hline 1 in. & $24 *$ & 12 & 11 & & & & & & & 12 & 11 \\
\hline
\end{tabular}

*includes chicks with "no descent" tested without shock. 
QUINTA, T. Use of an electrified center board in the study of chicks on the visual cliff. Percept. mot. Skills, 1966, 22, 169-170.

WALK, R. D. Visual cliff performance of human infants with the deep side 5 in. below the glass. Paper presented at meetings of the Eastern Psychological Association, Boston, Mass., 1967.

WALK, R. D., \& BOND, E. K. Deficit in depth perception of 90-day-old dark-reared rats. Psychon. Sci, 1968, 10, 383-384.

WALK, R. D., \& GIBSON, E. J. A comparative and analytical study of visual depth perception. Psychol Monogr., 1961, No. 75, 1-44, (Whole No. 519).
NOTES

1. This study was supported, in part, by a grant from the National Science Foundation (NSF GY 2765), and it was conducted while the second and third authors were undergraduate research participants.

2. A few animals were tested without shock, but the shortest latency was $35 \mathrm{sec}$ and the median latency was $4 \mathrm{~min} 1 \mathrm{sec}$ with some animals not descending from the center board in $10 \mathrm{~min}$. Most latencies with the shock procedure were between 30 and $40 \mathrm{sec}$, but $8 \%$ were over $1 \mathrm{~min}$, the longest was $1 \min 37 \mathrm{sec}$. 